\title{
Basic astronomy: common misconceptions and public beliefs according to the audience survey at Kyiv Planetarium.
}

\author{
Nataliya Kovalenko ${ }^{1,2,3}$ \\ ${ }^{1}$ Astronomical Observatory of Taras Shevchenko National University of Kyiv, 04053, Observatorna \\ str.3, Kyiv, Ukraine \\ ${ }^{2}$ Strömstad Academy, SE-45280 Strömstad, Sweden \\ ${ }^{3}$ Kyiv Planetarium, 03150, Velyka Vasylkivska 57/3, Kyiv, Ukraine
}

\begin{abstract}
Results of a Kyiv Planetarium audience survey are discussed. Kyiv Planetarium has a "Big Zeiss 4" projector, a fulldome projection system, a dome 23 meters across, and 300 seats. Having presented a program to up to 300 visitors at once, it is not easy to examine the general public understanding of basic astronomy, to get feedback on the program, and to estimate the educational impact on the public. Strategically designed questionnaires were used to find out what are visitors' personal experiences and previous knowledge. Questions in the questionnaire can be conditionally divided into several groups: - a) personal data (age, education); - b) astronomical knowledge and observational experience (attendance of astronomy lessons at school, observation of interesting astronomical phenomena such as eclipses, comets, meteors, experience of watching the sky through a telescope, age of the Earth and the Universe, reasons for seasonal changes and Moon phases, the brightest star, constellations that the visitor knows, number of planets in the Solar system, the biggest planet in the Solar system, how often do visitors read about space related topics); - c) visitors' personal beliefs like their attitude towards horoscopes and extra-terrestrial life; and - d) visitors' attitude towards planetarium itself, likes and dislikes, topics for future programs, expectations, sources of information about Planetarium, and number of their visits to planetarium. I discuss the results from 147 questionnaires that were gathered back, the most common misconceptions and public beliefs are revealed.
\end{abstract}

\section{Audience survey}

147 questionnaires were gathered from family visitors who were attending several planetarium programs on different days. The programs attended are: "Myths and legends of the starry sky", "Guests with tails - comets", "Dinosaurs - the great error of nature?", "Trip to the greatest observatories of the world", "Astro-Quiz". Results from the questionnaires are given below in Table 1 .

Besides basic statistics some cross-study has been done to compare the results and attitudes towards astrology/astronomy in such samples: $1^{\text {st }}$ time visitors to $3^{\text {rd }}$ and more times visitors. It was also interesting to see if there is any difference in astronomical knowledge and astrological beliefs depending on visitors' age, education, astronomy lessons at school, experience of observing through telescopes. Results of the cross-check study are given where appropriate. 


\section{Results}

The survey results (see Tab.1) show that many people visit the planetarium for the first time $(58 \%)$, while $26 \%$ have visited 3 or more times. Even first-time visitors have some basic astronomical knowledge (they marked that they read or listen from time to time to space news in the media). The easiest question for the audience was "What is bigger - the Earth the Moon - the Sun?", 98\% gave the right answer, while the most difficult question was about the age of the Universe (6\% of correct answers). The age of the Earth got $48 \%$ of correct answers. Surprisingly only $12 \%$ of respondents chose the wrong answer on the question about change of seasons (88\% correct), and $73 \%$ chose the correct answer about reason for Moon phases. Only 53\% called Jupiter the biggest planet. 23\% of our audience had astronomy lessons at school, and the same fraction has experience of observing through a telescope. Very few (27\%) named Sirius as the brightest star in the night sky, while 39\% said Polaris was the brightest. Most popular constellations are Ursa Major and Minor, Canis Major and Minor, and the Zodiac constellations (not surprisingly). Some visitors listed quite a lot of constellations, not only the most common, while other visitors invented their own constellations such as Polar Cross, Colliseum, the Pleiades, Snakes. 66\% mentioned they had observed phenomena like eclipses or comets. $56 \%$ believe in extraterrestrial life, and $68 \%$ believe in horoscopes.

Table 1. Results of the audience survey.

\begin{tabular}{|c|c|c|c|}
\hline & $\begin{array}{c}\text { All } \\
\text { visitors } \\
(\%)\end{array}$ & $\begin{array}{c}1 \text { st time } \\
\text { visitors } \\
(\%)\end{array}$ & $\begin{array}{c}\text { 3rd time } \\
\text { visitors } \\
(\%)\end{array}$ \\
\hline Percent of visitors & 100 & 58 & 26 \\
\hline $\begin{array}{c}\text { Age: } \\
6-10 \\
11-15 \\
16-20 \\
21-30 \\
\text { Above } 30 \\
\end{array}$ & $\begin{array}{c}38 \\
25 \\
14 \\
7 \\
16 \\
\end{array}$ & $\begin{array}{c}37 \\
31 \\
17 \\
10 \\
5\end{array}$ & $\begin{array}{c}42 \\
5 \\
11 \\
5 \\
37 \\
\end{array}$ \\
\hline Audience with education past high school & 25 & 21 & 37 \\
\hline Had astronomy lessons at school & 23 & 17 & 42 \\
\hline $\begin{array}{l}\text { Have experience of observing through } \\
\text { telescope }\end{array}$ & 23 & 17 & 47 \\
\hline $\begin{array}{c}\text { Have observed celestial phenomena } \\
\text { (eclipses, comets, meteors, strange celestial } \\
\text { phenomena - possible UFOs) }\end{array}$ & 66 & 57 & 74 \\
\hline Do believe in horoscopes & 68 & 67 & 63 \\
\hline $\begin{array}{c}\text { Reason for the Moon phases - correct } \\
\text { answers }\end{array}$ & 73 & 81 & 53 \\
\hline $\begin{array}{c}\text { Reason for seasons' change - correct } \\
\text { answers }\end{array}$ & 88 & 83 & 95 \\
\hline $\begin{array}{l}\text { The biggest planet in the Solar system is } \\
\text { Jupiter - correct answers }\end{array}$ & 53 & 50 & 58 \\
\hline Age of the Earth is about 4.5 billion years & 48 & 50 & 32 \\
\hline Age of the Universe is about 14 billion years & 6 & 10 & 5 \\
\hline $\begin{array}{l}\text { The brightest star on the night sky is Sirius - } \\
\text { correct answers }\end{array}$ & 27 & 19 & 37 \\
\hline Do believe in extra-terrestrial life existence & 56 & 52 & 74 \\
\hline
\end{tabular}




\section{Discussion}

The results correspond in general to the world trends published as a result of previous studies [4-15]. The cross-study reflected that the majority of categories of questions correlate with public knowledge of astronomy. For example, among $3^{\text {rd }}$ time visitors there are more people who had astronomy lessons at school (42\% vs. $17 \%$ in case of $1^{\text {st }}$ time visitors), had looked through a telescope (47\% vs. $17 \%)$, had observed interesting celestial phenomena (74\% vs. $57 \%$ ), do not believe in horoscopes (37\% vs. $33 \%$ ), are readers of astronomy magazines and web-sites (79\% vs. 60\%). More $3^{\text {rd }}$ time visitors in comparison to $1^{\text {st }}$ time visitors chose the correct answer for explaining why seasons change (95\% vs. $83 \%$ ), which is the biggest planet in the Solar System (58\% vs. 50\%), and which is the brightest star in the sky (37\% vs. $19 \%)$.

Surprisingly, fewer $3^{\text {rd }}$ time visitors in comparison to $1^{\text {st }}$ time visitors know about the reason for the Moon phases (53\% vs. $81 \%$ ). Fewer $3^{\text {rd }}$ time visitors know the age of the Earth $(32 \%$ vs. $50 \%)$ and the age of the Universe (5\% vs. $10 \%)$. More $3^{\text {rd }}$ time visitors ( $74 \%$ vs. $52 \%$ ) do believe in extra-terrestrial life existence. These unexpected trends are to be explained. May be the reason lies in the age distribution among $1^{\text {st }}$ and $3^{\text {rd }}$ time visitors: there are more people aged 6-10 years or above 30 in the $3^{\text {rd }}$ time visitors group. The younger ones may not yet know the answers, and the older ones may have forgotten the numbers (like age of the Earth or of the Universe) already.

In case of horoscope believers versus non-believers there is no correlation with higher education - education past high school (surprisingly, $72 \%$ of visitors with higher education do believe in horoscopes, and the fraction of people who believe in horoscopes among all visitors with all kinds of education amounts to $68 \%$ ). Similar situation is seen among those who observed celestial phenomena (73\% of horoscopes believers with observing experience vs. $68 \%$ of all the horoscopes believers), but some correlation exists with astronomy education at school (65\% vs. 68\%), experience of observing the sky through a telescope (59\% vs. 68\%), and number of visits to planetarium $\left(60 \%\right.$ vs. $68 \%$ in case of $3^{\text {rd }}$ and more times visit to Planetarium).

One may suggest that people with education past high school should be more critical thinking and less likely to be horoscope believers. According to our data, that suggestion is not supported $(72 \%$ of visitors with higher education do believe in horoscopes, and the fraction of people who believe in horoscopes among all visitors with all kinds of education amounts to $68 \%$ ). In spite of this difference with education is statistically insignificant at the level of $94 \%$, one explanation may be that people with higher education have access to more sources of information (for example, internet) in comparison to people with basic education. And these sources may be overwhelmingly contaminated with horoscopes predictions and astrological propaganda.

The biggest impact on believing in horoscopes based on the data, is the experience of observing the sky through telescope (59\% vs. $68 \%$ ), and number of visits to planetarium $(60 \%$ vs. $68 \%)$. Our data has shown that depending on age there are fewer horoscope believers among 11-15 years old children (61\% vs. 68\%), and adults above 30 years old (58\% vs. $68 \%$ ), while the critical number of $100 \%$ horoscopes believers is reached in the age group 21-30 years old.

As a conclusion, according to our data, it is statistically significant that people with astronomy experiences (observing the sky through telescope, higher number of visits to planetarium, astronomy lessons at school) are less likely to be horoscope believers. And correlation of higher fraction of horoscope believers among those with education past high school and among those who observed celestial phenomena (such as eclipses, comets, meteors, strange celestial phenomena - possible UFOs) is not statistically significant at the same level. 
The results will be used as a base for creating new and modifying already existing lectures and audio-visual shows, and for developing exhibits.

\section{Acknowledgments}

This material was a part of my science communication Master's Thesis. I appreciate the supervision by Lars Broman and Ernst van Groningen from Dalarna University and Klim Churyumov from Kiev Planetarium. I acknowledge the grant from Armand Spitz Fund for Planetarium Education that helped me to cover the study trip to Sweden as distance student in the Science Communication Master's Program of Dalarna University. I acknowledge the grant from IAU that allowed me to attend the ISE2A - the International Symposium on Education in Astronomy and Astrobiology.

\section{References}

1. J. Bell. Doing Your Research Project, A guide for first-time researchers in education and social science. Open University Press: Buckingham/Philadelphia (1999)

2. L. Broman. How to write a Master of Science Communication Thesis, Hogskolan Dalarna.

3. L. Broman. Selected papers on Science in Museums, Hogskolan Dalarna.

4. L. Danaia. Common Alternative Astronomical Conceptions Encountered in Junior Secondary Science Classes: Why Is This So? The Astronomy Education Review, Issue 2, Volume 6 (2007)

5. R. R. Hayward. The developing and field testing of an instrument using the planetarium to evaluate the attainment of the concept of annual motion. Presented at the 49th annual meeting of the National Association for Research in Science Teaching, San Francisco (1976)

6. T. Hessel. Justification of a Planetarium, pp.21-22, Planetarian December 2006, vol.35, No.4

7. L. Kelly. Front-end evaluation workshop. Notes from Presentation at the Visitor Centre Stage Action for the Future Conference, Canberra. April 24, 2004

8. http://amol.org.au/evrsig/evrconf.html

9. G. D. Kratzer. A survey of educators' perceptions concerning the impact of the STARLAB planetarium on teaching and learning. McNeese State Univ. independent research project (1997)

10. L. J. Rennie, T. McClafferty. Using visits to interactive science and technology centers, museums, aquaria, and zoos to promote learning in science. Journal of Science Teacher Education, 6 (4): 175-185 (1995)

11. C. Sumners. Quantification of student learning in the museum, planetarium, and IMAX theatre. pp.42-46, 15th International Planetarium Society Conference Proceedings, Montreal (2000)

12. S. A. Vahtera. Time and Space - A Science Education Experiment Based on Activity Learning Education. M.A. Thesis, October 1991, 72p. (29 app.) UNIVERSITY OF HELSINKI, Faculty of Education, Department of Teacher Education

13. M. Webb. Now what do they want? Planetarian June 2006, vol.35, No.2

14. RTDinfo Magazine on European Research, Special issue - November 2005 (http://ec.europa.eu/research/rtdinfo/special_euro/02/article_3150_en.html)

15. Science and Technology: Public Attitudes and Public Understanding http://www.nsf.gov/statistics/seind02/c7/c7s1.htm, http://www.nsf.gov/statistics/seind08/c7/c7s2.htm 